\title{
COMmercial Fiduciary Obligation
}

\author{
ROBERT FLANNIGAN*
}

The boundaries of fiduciary obligation continue to be the subject of much judicial discussion. One issue is whether, or to what extent, commercial relations should be regulated by fiduciary responsibility. The author examines the arguments and concludes that no justification exists for exempting commercial actors from fiduciary accountability.
Les limites de l'obligation fiduciaire continuent à susciter la discussion. Les juristes se demandent notamment si ou à quel point - les relations commerciales devraient être régies par la responsabilité fiduciaire. L'auteur examine les arguments et conclut qu'il n'y a pas lieu d'exempter les acteurs commerciaux de la responsabilité fiduciaire.

\section{TABLE OF CONTENTS}

I. INTRODUCTION . . . . . . . . . . . . . . . . . 905

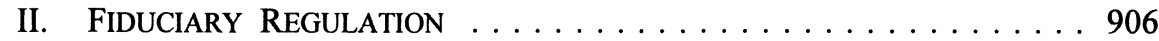

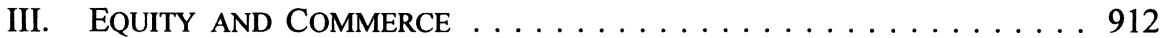

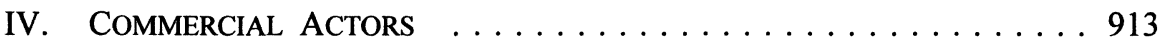

V. THE ARM'S LENGTH QUALIFICATION ... . . . . . . . . . . 915

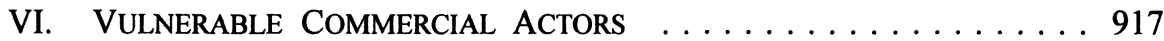

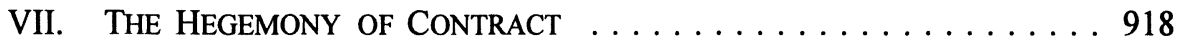

VIII. COMPLEX/UNCERTAIN REGULATION . . . . . . . . . . . . 919

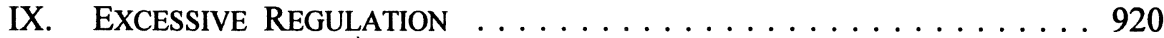

X. EXCLUSIVE BENEFIT .................... 920

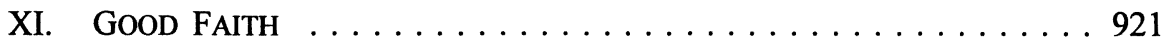

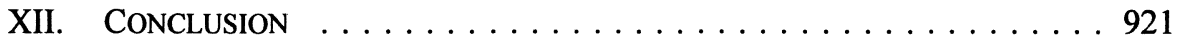

\section{INTRODUCTION}

It is commonly asserted that fiduciary responsibility can have little application to commercial relations. Several linked propositions, scattered throughout the jurisprudence, lever the advocacy of this broad generalization. Most of these propositions, however, provide no support whatsoever for a full or partial "commercial" exemption. Fiduciary obligation is a latent responsibility that properly applies throughout the entire commercial sphere. Given the mischief addressed, this form of social regulation is as fundamental to commercial arrangements as it is to any other type of arrangement that involves limited access to the assets of others. All of this will be explained in the course of an examination of the conventional default position. The analysis begins with an exploration of the policy foundation for fiduciary obligation. This provides a basis for the subsequent critique of the different propositions that have been advanced in the attempt to exempt commercial relations. The evaluation of these propositions leads to the conclusion that no justification exists for denying the application of fiduciary responsibility to commercial activity.

Professor of Law, University of Saskatchewan. I am indebted to Dennis Klinck and John McCamus for their comments on an earlier draft of the manuscript. 


\section{FIDUCIARY REgUlation}

Many judges and commentators regard fiduciary obligation as concerned with abuses of trust or confidence. By itself, however, this conceptual formulation can be easily misunderstood and probably has been more a source of confusion than a useful analytical construction. Read widely, the notion has a range that would coincide with at least one modern view of contractual obligation, where the contract form is understood as a socially-constructed channel or device that actors may employ to demonstrate (signal and bond) obligation or duty and thereby allow for the projection of exchange into the future. In that respect, a contract is an expression of mutual trust and a breach of the contract would be an abuse of trust. The idea is too narrow, on the other hand, because it implies that the absence of an actual trusting relationship is fatal to the existence of fiduciary status. It is quite clear that an actual subjective trust is not required. Generally speaking, the difficulty with the formulation is that it is too vague. It is necessary to supplement the basic idea by the application of more specific analytical propositions.

Fiduciary responsibility, like all forms of legal responsibility, is a product of social policy. In the fiduciary context, the operative social norm is the desire to inhibit opportunism. When actors undertake to act for others, they are often exposed to opportunities to benefit themselves or their associates. They may divert value away from their beneficiary or extract a coincident benefit. The permutations of this mischievous conduct are innumerable. We do not condone this self-advancement in the absence of the fully-informed consent of the beneficiary, and we impose strictures on those who are in a position to work this kind of mischief. Further, we recognize that the mechanisms of opportunistic conduct are often unappreciated or undetectable and we therefore make the fiduciary constraint a strict one. This regulation is applied on a default basis, allowing parties who wish to do so to contract for a different outcome they might have reason to prefer.

The common characteristic of persons generally acknowledged to be fiduciaries is that they possess access to property or assets for a defined or limited purpose. This includes cases of undue influence and breach of confidence. Austin Scott identified this basic characteristic when he described a fiduciary as a person who has undertaken to act in the interests of another. The requisite limited purpose is occasionally described as an altruistic one. This may be true in some instances. Parents, for example, act altruistically in the interests of their children. An altruistic purpose, however, is not a necessary condition for fiduciary status. The altruism notion describes a threshold level of self-abnegation that would prematurely close the fiduciary class. There is a permissible element of self-interest on the part of fiduciary actors that is not captured by the altruism term. Consider that neither agents nor employees normally regard their employment as an exercise in altruism. They understand their work to constitute an ongoing exchange of value between parties with self-serving objectives. In the case of a partnership, individual partners pursue the joint benefit of all partners in order to realize a personal share of that benefit. Parties negotiating a joint venture will release information to each other for the limited purpose of evaluating the prospective venture. Subject to that overriding purpose, the access (to information) granted to each of the 
parties is for the self-regarding purpose of assessing the viability of their own participation in the venture. The idea that the limited purpose must be an altruistic purpose would fail to accommodate these kinds of considerations or motivations. Instead, it is enough that the access is acquired, wholly or partly, to further the objectives of another person or institution. This is the essential characteristic of fiduciary access. The utility of describing this physical characteristic as a defined or limited access is that it conveys the idea that the access is functional and constrained (rather than casual or open), as well as specifying the boundaries of the potential mischief. When that physical characteristic (and consequent potential for mischief) is present, we impose on the actor an obligation to forgo any personal benefit not expressly contemplated by the grant of access. We do this to ensure the commitment of the actor to the external (other-regarding) purpose. The concern in this context is not that the actor may attempt, but fail to achieve, the external objective. Rather, our concern is that the realization of the objective might be compromised by the selfinterest of the fiduciary. An unqualified undertaking to pursue the interest of another [the physical characteristic] attracts a default obligation to serve selflessly [the imposed legal consequence]. The imposed obligation establishes a closed-system form of regulation. Within the range of the mischief made possible by the grant of access (the scope of the obligation), the fiduciary is not allowed to exploit the assets for personal benefit. The actor must first exit the fiduciary shroud. The only available exit mechanism, in most cases, is to secure the consent of the appropriate party.

No fiduciary issue can arise if access to property is unlimited. Where it is limited, however, the possibility of opportunism arises. There are at least three general ways in which an actor's commitment to achieving a defined purpose may be weakened by the prospect of personal gain or advancement. Each has been recognized and subjected to fiduciary regulation. The three correlative fiduciary propositions are that actors with limited access must not divert the value of the assets, they must not appropriate the residual value of the assets and they must not exploit related opportunities. If actors were permitted to take any of these actions, their pursuit of the extant limited purpose might be compromised. We consider each of these possibilities in turn.

The first concern with commitment involves those circumstances where the actions of the actor contravene or subvert the defined purpose of the access and directly injure the interests of the beneficiary. A trustee may sell assets that were intended to be conserved. A partner may arrange to take a personal benefit when purchasing partnership property. An employee may strip confidential information of its value by disclosing it to a competing enterprise. These circumstances involve direct departures from the defined purpose or defeat or injure the purpose or the beneficiary, and are easily understood as proscribed instances of opportunistic conduct.

The second way the commitment of an actor may be impaired has to do with the residual value associated with the assets. Most assets, by their further employment or exploitation, have a capacity to produce value beyond the limited purpose of the original access. An actor carrying out a limited purpose may find that the subject assets (e.g. equipment, information) will produce additional or collateral value, and might assume that this value may be taken personally so long as the limited purpose is 
achieved or pursued. A director of a corporation might trade on confidential or inside information relating to a planned reorganization or merger. A soldier might dress in uniform to shepherd smuggled goods through police checkpoints. The limited purpose is achieved in each case (corporate decisions made, military duties performed), but the actor has found a way to extract additional value. The actor is not entitled to retain this value. The concern with such conduct is that it will divert the commitment of the actor, consciously or otherwise, from the effectual pursuit of the defined purpose. The director, for example, may be pre-occupied with trading, rather than productive, considerations. More perniciously, the conduct may directly injure that which the limited access was designed to achieve. The director will corrupt the purpose of the access by making corporate decisions, not on the basis of corporate welfare, but to produce either positive or negative stock market swings in order to create opportunities to make trading gains. This kind of action obviously has the potential to injure the productive processes of the corporate undertaking. Similarly, the soldier's action has the effect of degrading the institutional values and objectives associated with the uniform. These potential mischiefs lead us to interdict such conduct by notionally allocating or assigning the residual capacity of the assets to the beneficiary. We do this through the imposition of the fiduciary injunction.

A third way in which opportunism may come into play does not involve the actor either directly diverting the subject assets or appropriating their residual value. Rather, the potential for opportunism arises if the actor may in the future acquire personal beneficial access to the subject assets, or to related assets. This is the area of business opportunities. Actors with limited access will be presented with opportunities to acquire the subject assets, or other related assets currently in the hands of third parties. If actors were allowed to take these opportunities, their commitment to the original purpose of the limited access may be displaced or weakened. A trustee might not vigorously seek renewal of a lease on behalf of an infant beneficiary if the possibility exists for the trustee to acquire the lease personally. Senior employees might delay or subvert projects of their employer if they were entitled to terminate their employment and bid for the work themselves. Individual partners might favour their personal interests if they were allowed to take up an opportunity in competition with the partnership. It does not matter in any of these cases that there was no actual opportunistic conduct or intent. The mere possibility that commitment was compromised is enough for us to require the actor to disgorge any profit. We cannot know whether the impulse of self-interest has operated in a given circumstance. A strict denial of profit is required because of the difficulties in detecting opportunism (or efforts to conceal it). There is, on the other hand, a limit to this denial of opportunity. Where the opportunity is unconnected or unrelated to the subject assets, and the beneficiary has no demonstrable interest or expectancy in it, the prospect of opportunism abates, and the actor is permitted to take it up.

These are the main ways in which opportunism may displace commitment on the part of those who have undertaken to act for others. Our attendant social regulation reflects a policy of unrepentant intolerance towards this kind of unilateral (unsanctioned) opportunistic action. The sweep of this regulation extends from the overt to the remote possibility of self-service. Where there is a limited access to property, and no 
concession has been sought, the social expectation is that the actor will remain faithful to the extant purpose. The assignment of fiduciary liability is the device we employ to ensure that our expectation will be met. This tedious concern with catholic temptation will seem less heroic than the virtuous correction of "abuses of trust," but this has been the traditional function of fiduciary responsibility, and the charged rhetoric in this area ultimately contemplates nothing more.

At its core, fiduciary responsibility is a practical jurisdiction, applying equally to both great and small failures, or potential failures, of commitment. Even a child sent to the store with a dollar to purchase a newspaper has, in strict conceptual terms, a fiduciary obligation to return with the spare change. A mechanic who uses a customer's vehicle for personal or business purposes would also be in breach of fiduciary obligation. It is the prospect of opportunism, not the magnitude of opportunism, that matters. The failure to appreciate this fact may partly explain the hesitation some judges have expressed in finding (or not finding) fiduciary responsibility. Judgments occasionally seem to proceed on the assumption that a particular mischief is not sufficiently worthy to attract fiduciary responsibility, or that fiduciary regulation is too high a standard to be applied in the circumstances. This hesitation likely exists because the rhetoric has had the effect of elevating or lionizing the fiduciary ideal in a way that makes it appear to some to be inappropriate for the seemingly less important instances of opportunism. Although intended to foster and support fiduciary responsibility, the rhetoric has in this sense perversely hindered its application.

This all may appear to constitute a rather capacious view of fiduciary responsibility. It is not unduly wide, however, if it is justified by the scope of the mischief we wish to suppress. Having said that, it is clear that there are definite limits on the scope of fiduciary obligation. These limits are incorporated in the view that fiduciary status is created by the acquisition of access for a defined or limited purpose. The main boundary principle is that there can be no fiduciary responsibility where the acquired access is unlimited. Simple purchases of property and unconditional gifts are obvious examples of this. A purchase or gift may be the impeachable consequence of a breach of fiduciary obligation, as where the transfer was the result of undue influence, but they do not themselves normally create fiduciary responsibility. The acquired access is unencumbered by any undertaking to pursue the objectives of others. These transactions each involve a grant of complete freedom to subsequently exploit the subject assets. Purchases and gifts are, of course, relatively straightforward instances of unlimited access. A second type of circumstance, where the access is temporary, may more usefully illustrate the difference between limited and unlimited access. Consider the difference between a monetary loan and a financial investment. In each case, one party grants to another a temporary access to monies. Usually, however, the loan will not attract fiduciary regulation, and the investment will. The difference is that the investment involves a grant of access to further the objectives of the investor, while the access granted to the borrower is unfettered. The borrower purchases the right to temporarily exploit the monies for personal purposes. This is so even where the loan is restricted to a particular purchase or use. To the extent the borrower is granted access, it is for a purely self-serving purpose. The security arrangements associated with a loan (e.g. mortgage, guarantee) typically also involve self-serving objectives on the 
part of both parties. Other lending relationships, such as that between credit card issuers and users, or basic deposit arrangements between banking institutions and their customers, are the same. Both the card user and the deposit-taking institution will invariably have full freedom to apply the monies (or credit) made available to them without having to pursue or accommodate some external purpose. Similarly, in the case of a lease, the lessee bargains for a self-serving access to the leased property. It is always possible, in each of these cases, that special factors or considerations, or more elaborate arrangements between the parties, will give rise to a fiduciary responsibility. The basic structures of these transactions, however, do not involve a limited access and are therefore not fiduciary in nature. Another type of transaction requires the pursuit of a defined purpose, but contemporaneously permits the grantee to exploit the assets in some way. The other-regarding component of this access will be fiduciary, but the agreement of the relevant party excuses or justifies the coincident specific exploitation of the assets for the personal account of the fiduciary. This is simply a manifestation of the principle that the informed consent of the grantor will cleanse any dealings of the fiduciary. The effect of all of this is that fiduciary regulation will not apply to the most common transactions that together make up the greatest part of our economic activity. Viewed in this light, there should be less concern with the supposed imperialistic inclination of the fiduciary jurisdiction. Fiduciary obligation is not an open-ended form of regulation. If our concern is the control of opportunism, the obligation applies only to physical arrangements of limited access.

This brings us to a point where a number of general observations will help to further clarify the operation of fiduciary regulation. The first observation is that fiduciary status is an independent or free-standing status. It is not contingent or dependent on the existence of some other status. While there are several nominate classes of actor that are considered to be "fiduciary," they have acquired this status because they each typically possess physical features that call for fiduciary regulation. Persons in these classes are therefore also fiduciaries. It is important to understand this point. It is actually a conflation of ideas to refer to a particular nominate status as a fiduciary one. The proper description would specify both the nominate status and the fiduciary status. Thus, a person is an agent and a fiduciary. Similarly, a person is a trustee and a fiduciary. In each case, fiduciary status is collateral and independent, arising directly from the nature (limited access) of the particular physical arrangement. So it is for partners, directors, guardians and all other nominate fiduciary categories. Further, it is undisputed that a fiduciary obligation may arise outside the various nominate categories if the actual relationship between the parties exhibits the relevant physical character. This confirms that fiduciary status is an independent status that is established by generic fiduciary characteristics, and not by characteristics necessarily unique or idiosyncratic to individual nominate categories. To the extent that an arrangement does exhibit peculiar physical properties, any implication for the regulation of opportunism will be addressed by a fiduciary analysis of those characteristics.

The second observation is that the fiduciary liability assignment supplies, along with our standard (and sometimes concurrent) contract and tort liability assignments, the basic legal content for the default liability structures of many common legal relationships. These individual assignments are the building blocks for the different 
liability structures. Their application in a given case depends on the nature of the physical arrangement the parties have constructed for themselves. An agency, for example, has a unique liability structure with particular contract, tort and fiduciary liability assignments. Properly authorized agents in a disclosed agency have no contractual liability to third parties, but are personally liable for torts they commit. Principals are alone liable on authorized contracts, and are vicariously liable for the torts of their agents. As well, agents are liable for breaches of the fiduciary obligation they owe to their principals. The liability structure for a sole proprietorship is different. Proprietors act on their own behalf and have open contractual and tort liability. There is no fiduciary responsibility, obviously, because proprietors pursue only their own objectives. The trust liability structure is again different. Trustees are regarded as principals relative to third parties (like sole proprietors), and therefore have open contract and tort liability. Unlike sole proprietors, however, their task is to pursue the interests of their beneficiaries. Consequently, they are fixed with a fiduciary responsibility. All of these liability assignments, in each of these structures, are premised on the operation of general social policies concerned with regulating risktaking and opportunism. The fiduciary liability assignment, in particular, is an elemental building block or generic design component that is employed along with other liability assignments in sometimes complex arrays to create the contextualized liability structures of our various legal relationships.

It should be apparent, at this point, that fiduciary responsibility represents a general head of obligation in much the same way that contract and tort are general heads of obligation. This is an inescapable fact and must always inform our approach to fiduciary issues. We lose track of this, it seems, when we ask whether a particular relationship is fiduciary. It is preferable to ask whether there are fiduciary obligations arising from a specific physical arrangement. A mechanic is not generally considered to be in a fiduciary relationship with customers. Yet a mechanic will have, along with certain contract and tort obligations, certain fiduciary obligations. In that sense (and to that limited extent), the relationship is fiduciary, but we are perhaps less likely to recognize this if our analysis is directed towards determining whether the overall relationship is fiduciary. Fiduciary obligation is a general head of obligation in the mechanism of its application (it is a "dimension" of a relationship) and, arguably, it ranks equally with the other two main heads of obligation both in terms of its scope and its social impact. Fiduciary responsibility is not some specialized doctrine employed only to control egregious abuses of high loyalty. It is not a peculiar equitable interference with regular social relations. Nor is it a sub-category of the law of restitution. Rather, it is an independent general form of social regulation. Contract, tort and fiduciary responsibilities are everyday obligations, and are justified by a widespread social consensus as to their utility. There is no reason to fear the principled application of fiduciary regulation. Properly understood, it only requires that we not act opportunistically towards those we have undertaken to serve. This is what must be kept in mind as we examine the various propositions that have confused the application of fiduciary obligation in the commercial sphere.

Finally, it must be understood that we install this regulation, and that we define its boundaries. The limits of fiduciary responsibility cannot be "found" or "discovered," 
they must be constructed. The issue of commercial application is a boundary question. We must answer this question based on our view of the nature of the mischief we seek to regulate. If our concern is the prospect of opportunism, then certain boundaries are implicated. If opportunism is not our true concern, or if there are reasons to relax that concern, other boundaries presumably would be appropriate. It is plain, at any rate, that we cannot define boundaries without first identifying our basic concern. The premise for the following discussion is that opportunism is indeed our primary concern and that it ought to be regulated throughout its full range of operation, including its commercial operation.

\section{EQUITY AND COMMERCE}

The question of the commercial application of fiduciary obligation is sometimes raised in the context of a broader debate over the application of "equity" generally in commercial law. Agglomerating all equitable doctrines together, the basic argument is that the introduction of equitable principles or considerations creates uncertainty and complexity in commercial relations. There are a number of difficulties with this argument, not the least of which is the incorrect assumption that commercial relations have traditionally not been subject to significant, even extensive, equitable regulation. The more fundamental observation, however, is that the issue of the commercial application of a given equitable jurisdiction cannot properly be resolved by argumentation at this broader, agglomerated, level. Instead, each equitable doctrine must be evaluated in terms of the specific function it is intended to serve. There may well be valid reasons for judges to refuse or hesitate to apply particular equitable principles. Presumably, however, those reasons will be specific to those particular doctrines in the identified circumstances. An analysis at the level of "equity" is undifferentiated and acontextual in this sense and therefore of little value. Nevertheless, the broader proposition is occasionally put forward in the effort to limit the commercial application of fiduciary responsibility. For some judges, it seems to imply or justify a sort of informal presumption against fiduciary accountability. In the following discussion, we proceed directly to the fiduciary issue, rejecting entirely the idea that the equitable origin of this jurisdiction has any relevance per se to the question of commercial application. The current validity of any form of legal regulation ultimately depends only on its present demonstrable social utility.

The attempt to dissociate "equity" and "commerce" is also problematic in view of the absence of a sharp boundary between commercial and other (non-commercial) activities. The commercial content of a transaction or relationship is only a matter of degree. Purely commercial and purely non-commercial arrangements are found at the extreme ends of one continuum that has no evident conceptual break. This alone indicates that the attempt to limit fiduciary responsibility to the non-commercial sphere is a misguided exercise. When we then view the matter in terms of the mischief involved, it is clear that opportunism is a mischief that is independent of the commercial or non-commercial nature of the acquired access. Actors are no less likely to act opportunistically because the setting is a commercial one. Accordingly, if the function of fiduciary responsibility is to regulate opportunism, there is no natural "commercial" exception. 
If a commercial exception cannot be distilled from the mischief itself, some other strategy must be employed to establish the supposed commercial boundary. The main approach has been to assert that there is something about "commerce" or "commercial actors" that is inconsistent with fiduciary responsiblity. The usual assertion is that fiduciary accountability does not (or should not) arise between commercial actors who deal with each other at arm's length. This is the first proposition we will examine. We initially investigate the commercial actor element, and then the arm's length qualification.

\section{COMMERCIAL ACTORS}

Conceding that the mischief is the same throughout, it might yet be argued that a commercial exemption is justified by the character of the parties. The argument would be that commercial actors are able to take care of themselves, and that their preference is to be subject to the least amount of legal regulation. This argument, though of ancient vintage, has always been specious. Commercial actors, like the rest of us, are selective in their subjective desire to be free of legal regulation. As a general rule, and quite naturally, most actors invite regulation that reduces their costs (or increases competitors costs), and seek to avoid regulation that increases their costs (or reduces competitors costs). If this is the relevant calculation, the application of fiduciary obligation to commercial relations will depend on whether it is regarded as a net benefit or net cost by the commercial sector as a whole. This is an empirical question, firstly, and it is not at all clear that informed commercial actors would instinctively jettison fiduciary responsibility. There is one other obvious conceptual problem with this character proposition. The argument involves a shift in focus from the actions of individual fiduciaries to the general characteristics or attributes of the commercial class. This displaces the traditional focus on the conscience of the individual mischievous actor. No explanation is offered for this shift.

The most significant conceptual impediment to the adoption of a commercial exemption is the existing widespread application of fiduciary responsibility in the commercial area. A number of the traditional status fiduciary classes have a substantial commercial operation. These include the principal/agent, trustee/beneficiary and solicitor/client relationships. A number of other status categories, such as partner/partner and director/corporation, are exclusively commercial. In fact, every modern business organization form (e.g. corporation, partnership, limited partnership, business trust, cooperative) incorporates fiduciary responsibility. In the case of the corporation, the new regulation associated with the statutory oppression action replicates, and then extends well beyond, the ambit of traditional fiduciary responsibility. Accordingly, when commercial actors select a business form, they select fiduciary responsibility. As amongst themselves, their preference is for fiduciary accountability. Even in the resource sector, commonly regarded as the prototypical entrepreneurial industry, actors will regularly select fiduciary accountability when arranging a joint undertaking. They will choose one of the forms mentioned above or they will form what they call a "joint venture," a structure which has the fiduciary character of a partnership. They might also enter into a joint operating agreement, in which case the operator will owe fiduciary obligations to all of the parties. Generally, in the resource sector, actors recognize the 
default application of fiduciary responsibility and deal with it through acceptance (e.g. remaining silent), clarification (e.g. "area of mutual interest" clause) or exclusion. It is worth noting that when the parties intend to exclude this regulation (usually where retail investors or weaker actors are involved), they sometimes attempt to do so indirectly by asserting that they are merely co-owners or independent contractors and that, consequently (implicitly), they have no fiduciary duties to one another. This, however, may be ineffective if the status assertion is ambiguous. Where that is the case, and the parties begin to jointly develop the property so as to constitute themselves partners, they will be fiduciaries by default.

Commercial actors do accept fiduciary accountability amongst themselves and, of course, they insist on it from their agents and employees. It is not difficult to understand why this is so. All of us, whether acting in a commercial capacity or not, expect a minimal level of commitment from those who serve us or participate in our projects. We expect those who have limited access to our assets to forgo taking an unauthorized benefit for themselves. There is, on the other hand, a certain unease with what seems to be the shifting nature of this jurisdiction. Commercial actors may fear that they will be liable for not doing, or caring, enough (in some maternal sense), or for not meeting the objectives of the limited access. These ideas, however, are very different from the opportunism concern that is the traditional foundation for fiduciary obligation. We want to ensure commitment, not punish those who engage their undertaking but choose not to go beyond it, or, for benign reasons, ultimately fail to achieve the intended objective.

It is clear that commercial actors are concerned with the possibility of opportunistic action on the part of their co-venturers and workers. The economic literature on agency costs (the costs of opportunism) indicates that the manifestation of this concern even surpasses, in two senses, the existing legal [fiduciary] regulation. First, because commercial actors view the fiduciary liability assignment as an inadequate regulator of opportunism, they turn to contractual arrangements to try to align the interests of the fiduciary with their own. A large part of the economic literature investigates the details of this project. Secondly, commercial actors use the economic or physical properties of business organization forms (rather than their legal properties) to control opportunism. In economics, the "firm" is regarded as a structure through which an actor exercises control over a collection of assets. The control structure of the firm is contrasted with the market (or exchange), where the parties relationship is one of bargaining or negotiation. Within firms, opportunism on the part of directors, officers and other workers will adversely affect production. This standard form of opportunism, which we may call production opportunism, is subject to basic fiduciary regulation. There is another form of opportunism between firms, however, that is not generally legally regulated (because it does not occur in the context of a limited access). We may call this "exchange" opportunism. It is the opportunism that operates at the exchange interface between firms. The standard example of this kind of opportunism involves one firm making large unique investments in assets to fulfill its obligations under a particular contract. The opportunism occurs when the contracting parties enter into negotiations to renew the contract. The party who has sunk capital into assets that are not easily turned to other uses is in a vulnerable position. The other party recognizes 
this and will refuse to renew unless concessions are forthcoming. Commercial actors react ex ante to the prospect of exchange opportunism in some cases by replacing the exchange relationship with a control relationship. They do this through vertical integration of the particular production step. That is, they extend the scope of their firm. They use or extend the physical properties of the firm (its control structure) to reduce exchange opportunism, essentially by replacing it with the more manageable production opportunism.

We may add here a further observation with respect to the distinction between exchange and production opportunism. The different legal reaction to these forms of opportunism corresponds with the limited access basis for fiduciary responsibility. We do not regulate exchange opportunism because exchanges, by their nature, involve parties who are looking exclusively to their own self-interest. Actors may, as their part of the exchange, give their undertaking to act for another, but the immediate exchange process is purely self-interested on both sides. Parties must therefore anticipate and address exchange opportunism, or suffer its effects. It is different with production opportunism, where workers acquire access to property (as an incident of their employment contract) in order to serve the interests of the firm. Because of this limited purpose, workers are subjected to fiduciary responsibility. The default rule we impose requires workers to seek approval if they are to take a benefit. More generally, this identifies an important feature of the nature of the relationship between contract law and fiduciary obligation. In the absence of undue influence, the contracting process itself does not attract fiduciary responsibility, but contracts may be the source of fiduciary obligation if their function or effect is to arrange access for a defined or limited purpose. Bargaining (exchange) is invariably self-serving. It is what attends, or is produced by, bargaining that may or may not attract fiduciary responsibility.

There can be little doubt that opportunism is a concern throughout the commercial sphere, that commercial actors are keenly aware of it, and that they regularly go beyond the existing legal regulation in their efforts to control it. This tends, in retrospect, to make our legal efforts to control opportunism (by the fiduciary liability assignment) seem modest and inadequate. The conclusion from all of this, in any event, is that the commercial status of actors is ultimately of little significance. The relevant distinction is not between commercial and non-commercial arrangements, it is between limited and open access. Actors only remain free of fiduciary responsibility if their access is exclusively for self-serving purposes. To the extent their access is limited, they are fiduciaries. If our concern is opportunism, this is the proper distinction.

\section{THE ARM'S LENGTH QUALIFICATION}

The second component of the main exempting proposition is that the actors are in an arm's length relationship. This qualification purports to limit the number of commercial interactions that will be excused from fiduciary regulation. Unfortunately, the meaning to be attributed to this limiting factor is unclear. It must first be understood that the arm's length concept is both a factual condition and a legal construction. Many judges do not seem to appreciate this. They assume that the issue is purely factual. In some instances, the bare assertion that the relationship was an arm's length one 
constitutes the whole of the judicial analysis. The difficulty with this is that there is no consensus with respect to the factual arrangements that are contemplated by the legal employment or appropriation of this term. In fact, attempts to specifically define "arm's length" for the purposes of fiduciary responsibility are virtually non-existent. The arm's length vessel has yet to be filled. Until that occurs, the invocation of the "arm's length" terminology will only beg the question.

Taxation is the one area of the law where the arm's length concept has been developed in some detail. In that context, however, we find that it has a different function. The revenue authorities have concluded that a transaction will not be at "arm's length" if a common mind directed the bargaining of both parties to the transaction, the parties acted in concert without separate interests or one party was in de facto control of the other. The concern of the revenue authorities is that two (or more) taxpayers may collude or act together to structure or manipulate their transaction so as to impair the realization of tax claims or objectives. This concern, obviously, is very different from the concern in the fiduciary context, where the mischief is that the persons involved will act, not together, but against the interests of each other. This difference suggests that the tax concept may not be wholly transferable to the fiduciary context. Certainly there are few references to the tax jurisprudence in the fiduciary cases.

Although not directly relevant, there are themes running through the tax literature that likely reflect the general professional understanding of the arm's length idea. The basic content of these themes replicates, or comes very close to, the limited access basis for fiduciary responsibility. One theme is that persons do not act at arm's length if they have the same economic interest in achieving a common objective. This corresponds to the limited/open access distinction. Parties who acquire open access have only selfserving objectives. A fiduciary, on the other hand, has undertaken to pursue the objectives of another party and, in that sense, has the same interest in achieving the common objective. Fiduciaries align their own economic interests (wages, fees, share of profits) with the interest of the other party in order to pursue what is now their common objective. A second theme is that arm's length relationships are characterized by the presence of ordinary commercial tensions, while non-arm's length relations are not. This also corresponds with the limited/open access distinction. Parties with selfserving objectives bring ordinary commercial tensions to their interactions. Where a fiduciary relationship is created, however, ordinary commercial tensions are suspended to the extent of the limited access. Again, the parties have aligned themselves to serve what is now a common objective, and their interaction is cooperative, or less vigilant, within the framework of the defined objective.

It should be appreciated that the arm's length qualification, at this point in its development in the fiduciary context, is a restatement of the question (rather than an answer to the question). We cannot know which persons are fiduciaries until we define what we mean by "arm's length." This takes us back to a consideration of the mischief involved. Once identified, the only question is whether there is an interpretation of arm's length that corresponds with the boundaries of that mischief. The mischief involved (the purpose of the regulation) necessarily defines the scope of fiduciary responsibility. If opportunism is the mischief we seek to regulate, arm's length 
relationships must be those that do not involve one party acquiring limited access to the property of another. In this way we mould the arm's length concept to track our opportunism concern. An incidental observation here is that the current references to "commercial actors dealing at arm's length" imply that the arm's length qualification does not apply to non-commercial parties. However, once we define arm's length in terms of unlimited access, it should be evident that the qualification is a general one, applying whether the setting is commercial or non-commercial. The distinction between fiduciary and other relationships is then simply the distinction between arm's length (open access) and non-arm's length (limited access) relations.

\section{Vulnerable COMmercial ACtORS}

Particular boundaries are defined by an exemption limited to commercial actors dealing with each other at arm's length. A different boundary is identified when it is asserted that fiduciary obligations apply only to "vulnerable" commercial actors. This is not always clear in the cases, however, as references to the vulnerability criterion tend to be run together with references to commercial context, arm's length and other factors. It should also be pointed out that the vulnerability criterion is not employed specifically to support a commercial exemption. It is supposedly a general basis for distinguishing between fiduciary and non-fiduciary relations. Nevertheless, if it is a valid consideration, it would alter the range of transactions that fit within a commercial exception to fiduciary obligation.

The difficulty with the vulnerability criterion is its indeterminate meaning. There are two quite different conceptions of what it means to be vulnerable in the fiduciary context. One formulation, corresponding to the standard lay usage of the term, would characterize persons as vulnerable if they are burdened by a pre-existing weakness or disability (relative to others) that affects their ability to protect their own interests. Sometimes this idea is framed as a difference between commercial actors who are sophisticated and those who are not. At other times it is framed as an inequality of bargaining power. This sense of vulnerability is essentially a replication in the fiduciary context of the doctrine of unconscionability. As such, it is subject to the same substantial criticisms that are levelled at that notoriously uncertain and conceptually problematic contract doctrine. Furthermore, there is no inherent congruence between sophistication or economic power on the one hand, and opportunism, on the other, and it is unclear exactly what other mischief might be contemplated. This view of vulnerability must be discarded until a coherent justification for its application is forthcoming.

There is another interpretation of vulnerability that can be found in the fiduciary cases. Persons are vulnerable because, by employing others to pursue their interests, they have exposed themselves to the possibility of opportunistic action. Vulnerability in this sense is exposure, not weakness. This interpretation permits recognition of the fact that even sophisticated and powerful commercial actors are regularly exposed to the possibility of opportunism by their co-venturers, advisors, and workers. This view may also be equated with the limited access basis for fiduciary responsibility. A person who grants access to another for a defined or limited purpose is "vulnerable" to a 
diversion of the value of the subject assets. Accordingly, if opportunism is our concern, it is possible to describe the issue as one of vulnerability in this specific sense. It may be doubted, however, whether there is any advantage in doing so. The vulnerability term is by itself too vague and open-ended, particularly in lay terms, to serve as a general test for the imposition of fiduciary responsibility. A good deal of elaboration and qualification is required before the vulnerability term can be made to coincide with the more constrained idea of limited access.

\section{The Hegemony OF CONTRACT}

A number of propositions occasionally offered to support a commercial exemption draw on the view that contract is ascendent in the commercial context. One proposition is that commercial actors set their own bargain and, consequently, if they do not contract into fiduciary responsibility, it does not govern their arrangement. This argument amounts to a refusal to recognize (or perhaps appreciate) the default operation of the fiduciary jurisdiction, and, for that reason, is untenable. Contracting is itself associated with a set of default rules that apply unless the parties agree otherwise. It is no different where default fiduciary rules are also activated because the contract provides for a limited access. Fiduciary regulation applies whenever the requisite physical arrangements exist between the parties. It is a question of status. If no third party effects are involved, the contracting parties may exclude the regulation associated with their legal status, but this must be done expressly or implicitly. The mere fact that they have contracted with each other cannot be taken as a disavowal or rejection of the default regime. Moreover, it should be apparent that this argument ultimately depends on some unstated difference between commercial and other actors (because the power to contract is not limited to commercial actors), and this once again forces us back to a consideration of what that difference might be.

A second proposition concedes the default operation of fiduciary regulation but insists that such responsibility is ousted if the relationship is contractual and the terms of the contract are complex or detailed. The argument is that complexity and detail, which are supposedly more characteristic of commercial contracting, imply that the parties sought to comprehensively specify the nature of their relationship and therefore the absence of fiduciary duties in the contract signifies their intention to exclude that jurisdiction. This is a curious analysis. Precisely the opposite conclusion is more plausibly extracted from these considerations. If the complexity and detail of the contract implies that the parties were aware of undesirable default rules, the absence of fiduciary provisions must be taken to indicate their acceptance of the content of the known default regulation.

As mentioned, these propositions reflect a view of contract as privileged or ascendent in the commercial sphere. It is true that parties may, within broad limits, set the terms of their own private arrangement. However, this ascendency must be defined by clear agreement between the parties if all or part of the socially-imposed default regime is to be displaced. Most contracting parties understand this. The prudent course of action, accordingly, is to expressly address what fiduciary obligations, if any, the parties are to have. The use of an "area of mutual interest" clause is an example of this. Other 
express, but indirect, techniques such as status assertions or "entire agreement" clauses might be employed, but their effectiveness is questionable. Only to the extent the modification or exclusion of the default regime is manifest will the intended ascendency of the contract be established. In that context, neither the power to contract nor actual detailed contracting, per se, suggest that there ought to be a commercial exemption from fiduciary obligation.

\section{COMPLEX/UNCERTAIN REGULATION}

Complexity and uncertainty are two standard objections to any kind of commercial regulation. They are real concerns in the fiduciary context in at least one sense. The fiduciary jurisprudence (and literature) is not characterized by a common nomenclature or shared linguistic tradition. As a result, there appears to be a morass of competing analytical structures and conclusions. This creates an impression both of complexity and uncertainty, even though the views actually expressed are conceptually straightforward and differ, for the most part, in only marginal ways. The source of the problem, on this view, is not fiduciary regulation itself, but its analytical presentation. This kind of concern with complexity and uncertainty would largely evaporate upon the adoption of a common rhetoric.

In other respects, these objections do not amount to a serious concern. It may first be questioned whether the complexity argument is at all plausible. The supposed complexity of fiduciary responsibility has never actually been demonstrated. The essence of the obligation is simply to forgo any unauthorized personal benefit when acting in the interests of another. This is not overly complex. We all understand this intuitively, although, after the fact, we may well feel justified in our own opportunistic actions. A second observation is that commercial actors, more so than the rest of us, deal regularly with complex regulation. Consider the far more complex business organization, competition and taxation rules that govern the actions of commercial actors. A third observation is that complexity is justified if the benefits of a more nuanced or complete regulation exceed the implementation, comprehension and compliance costs of the complexity. It is necessarily always a cost/benefit issue. The complexity objection lacks an empirical foundation.

The uncertainty argument is most often a claim of confusion in the jurisprudence. However, it may also be a claim that commercial actors are better served by bright line rules rather than by general principles that are context dependent. One difficulty with this argument is the underlying assumption that commercial actors are not generally subject to contextual regulation. A second difficulty is that this argument does not by itself support exempting commercial relations from fiduciary regulation. If it is a valid proposition, it would require only that whatever commercial fiduciary regulation we impose, we structure it in the form of sharp rules to the extent possible. In one sense, this is already the case. The traditional identification of status categories of fiduciaries involves sharp presumptive rules (e.g. "directors" are fiduciaries). Outside the status categories, however, contextual sensitivity is required because other physical arrangements are not typically fiduciary in character. Even then, the contextual analysis operates on the basis of what is a relatively sharp test - whether the access is limited 
or open. None of this, however, is intended to concede the validity of the original proposition. It cannot be said that sharp rules are preferable in all, or even most cases. Arguably, when liability assignments are at issue, a contextual analysis will almost always be preferable because of its superior targeting capability. Contextual analysis is ultimately dominant throughout the fiduciary area, in any event, because a factual analysis may be employed to rebut the traditional presumptive status characterizations.

\section{EXCESSIVE Regulation}

Another standard tactic employed to contain any kind of legal regulation is to urge caution in its application lest its overapplication undermine its legitimate aspirations. This argument appears frequently in discussions of fiduciary responsibility, particularly with reference to its commercial application. It is, however, an empty objection. The argument is conditioned on the existence of a state of ignorance. It can only be raised where the objectives of the regulation are unclear. If the objectives are unclear, however, the problem is either one of uncertainty or a lack of social (or judicial) consensus. The excessive regulation argument, by itself, offers no substantive contribution to the analysis of the scope of fiduciary responsibility. It tells us nothing about whether or why a particular instance of regulation is excessive. Where it appears in discussions of fiduciary accountability, it is but evidence of analytical weakness.

Fiduciary responsibility is also said to be excessive in a remedial sense. The available equitable remedies are said to be harsh, draconian, or unnecessarily powerful in a commercial context. This argument is flawed in a number of respects. It must be obvious, firstly, that the remedial consequence cannot drive the original liability determination. Both are instead driven by the singular assessment of the mischief involved. Only the purpose of the regulation can define its scope or remedies. A second difficulty with the argument is that it is far from clear that fiduciary remedies are harsh or unjustifiably powerful. Presumably they will have a proportionate and discretionary application. Judges often speak of the "flexibility" of equitable remedies and the possibility of tailoring them to specific circumstances. Moreover, we do not "punish" fiduciaries by requiring them to disgorge their unauthorized gains. Equitable remedies may perhaps appear to be "draconian" next to a simple award of damages, but that is largely because the damages remedy is a relatively weak one. It allows breaching parties to retain profits which exceed the damages payable to the innocent party. A good deal of criticism has been directed at this "efficient breach" aspect of the damages remedy. More generally, the real significance of the traditional availability of powerful remedies in this area is that we have always been particularly troubled by the opportunism mischief and we have attempted to remove any incentive to act opportunistically.

\section{EXCLUSIVE BENEFIT}

Surprisingly, it is still sometimes suggested that fiduciary obligation is incompatible with the mutual beneficial exchange associated with commercial interaction. The idea seems to be that uncompromising self-denial is a necessary characteristic of fiduciary status. This presumes a view of fiduciary responsibility that has never existed. The 
supposition that fiduciaries must be volunteers is absolutely false. They are entitled to benefit to the extent they have been authorized. It is solely a question of proper consent. Their benefit may be taken from a favourable transaction, an agreed wage, a share of profits, or in any other form. Indeed, there is no limit to the benefit they may take from their fiduciary office so long as it is unambiguously specifically authorized ex ante or ex post.

\section{GoOD FAITH}

A popular reaction today to the supposed uncertainty, over-application or strictness of fiduciary obligation is to propose an intermediate (or different) level of regulation fitting somewhere between the perceived extremes of fiduciary regulation and no regulation. This intermediate regulation is typically cast as a duty of good faith. The significant difficulty with this proposal is that, at this point, the notion of good faith is undeveloped and seriously controversial. It would appear to be quite unattractive, in this respect, to commercial actors. They would undoubtedly prefer the current conventional jurisdiction to a more complicated tiered regime that incorporated the problematic good faith standard.

For many years now, commentators have debated the utility of a duty of good faith in the general law of contract. The notion continues to be questioned even in those jurisdictions where it has achieved a limited recognition. No consensus exists. The issue is even more problematic in the fiduciary context because fiduciary responsibility has itself traditionally been described in terms of good faith. Consequently, if the good faith standard is to be applied, it is necessary to differentiate it from the fiduciary standard, as well as to identify its basic rationale. It is of course our prerogative to choose to establish an intermediate standard to regulate our conduct towards each other. We must, however, be clear about the nature of the mischief that concerns us. Is it the same opportunism mischief, or some other concern? Is it our intention to apply different levels of regulation to different degrees of the same mischief? How would we construct a distinction between degrees of opportunism? Is our intention instead to apply a different level of regulation to a different set of boundaries? Would we, for example, wish to apply only the good faith standard to opportunism in commercial relations, reserving the fiduciary standard for non-commercial relations? Does this not take us back once again to a consideration of the nature of the mischief, and whether that mischief changes in some way as we pass over the unclear boundary between commercial and non-commercial relations? This kind of analysis needs to be undertaken at some point. To date, the judges who have tinkered with the good faith standard have not done so in any sort of satisfactory way.

\section{Conclusion}

The traditional function of fiduciary responsibility was to control opportunism by those who had undertaken to serve the interests of others. That task was pursued across the range of human endeavour. Often the analysis was intuitive and analogical. More recently, judges and commentators have focused on defining in abstract terms the generic physical characteristics that attract fiduciary regulation. One part of this exercise 
involves a discussion of the applicability of fiduciary responsibility to commercial relations. Several specific propositions have been advanced in support of a commercial exemption. When examined, however, these propositions fail to establish a convincing foundation for the asserted exemption. A proper analysis of this issue would begin with an investigation of the concern that underlies fiduciary responsibility. Arguably that concern continues to be the regulation of opportunism. If so, the boundary between fiduciary and non-fiduciary relationships is defined by the distinction between limited and open access. That distinction does not contemplate a commercial exemption to the general default application of fiduciary accountability. 